\title{
Transient Receptor Potential Vanilloid 1 Is Required for Intrinsic Osmoreception in Organum Vasculosum Lamina Terminalis Neurons and for Normal Thirst Responses to Systemic Hyperosmolality
}

\author{
Sorana Ciura and Charles W. Bourque \\ Centre for Research in Neuroscience, Montreal General Hospital and McGill University, Montreal, Quebec, Canada, H3G 1A4
}

Recent studies have indicated that members of the transient receptor potential vanilloid (TRPV) family of cation channels are required for the generation of normal osmoregulatory responses, yet the mechanism of osmosensory transduction in primary osmoreceptor neurons of the CNS remains to be defined. Indeed, despite ample evidence suggesting that the organum vasculosum lamina terminalis (OVLT) serves as the primary locus of the brain for the detection of osmotic stimuli, evidence that neurons in the OVLT are intrinsically osmosensitive has remained elusive. Here we show that murine OVLT neurons are intrinsically sensitive to increases in the osmolality of the extracellular fluid. Hypertonic conditions provoked increases in membrane cation conductance that resulted in the generation of an inward current, depolarizing osmoreceptor potentials, and enhanced action potential discharge. Moreover, we found that this osmosensory signal transduction cascade was absent in OVLT neurons from TRPV1 knock-out $\left(T R P V 1^{-1-}\right)$ mice and that responses of wild type (WT) OVLT neurons could be blocked by ruthenium red, an inhibitor of TRPV channels. Finally, TRPV1 ${ }^{-1-}$ mice showed significantly attenuated water intake in response to systemic hypertonicity compared with WT controls. These findings indicate that OVLT neurons act as primary osmoreceptors and that a product of the trpv1 gene is required for osmosensory transduction.

Key words: hypothalamus; electrophysiology; thirst; osmoreceptor; TRPV; OVLT

\section{Introduction}

Systemic osmoregulation involves balancing water intake and excretion through the central control of thirst and vasopressin secretion (Andersson et al., 1982; Denton et al., 1996; McKinley et al., 2004a,b). Appropriate regulation of these responses depends on specialized osmosensory neurons that transduce osmotic stimuli into electrical signals that can ultimately modulate homeostatic effector neurons via synaptic contacts. Although osmoresponsive neurons are found in many parts of the CNS (Bourque et al., 1994), previous studies have established that the primary homeostatic osmosensor of the brain is located in the organum vasculosum of the lamina terminalis (OVLT) (Johnson and Gross, 1993; McKinley et al., 1999), a circumventricular organ located at the rostral ventral border of the third ventricle. Lesions encompassing the OVLT abolish the osmotic control of thirst (Buggy and Johnson, 1977; Bealer et al., 1979; McKinley et al., 1982) and vasopressin release from the neurohypophysis

Received Feb. 27, 2006; revised July 18, 2006; accepted July 24, 2006.

This work was supported by a Canadian Institutes of Health Research (CIHR) operating award, a CIHR Senior Investigator award, and a James McGill Research award to C.W.B. and by Studentship awards from the McGill University Health Centre Research Institute and the Faculty of Medicine of McGill University (S.C.). We thank R. Sharif Naeini for help with measurements of serum osmolality and for helpful comments on this manuscript.

Correspondence should be addressed to Dr. Charles W. Bourque, Division of Neurology, Room L7-216, Montreal General Hospital, 1650 Cedar Avenue, Montreal, Quebec, Canada, H3G 1A4. E-mail: charles.bourque@mcgill.ca.

DOI:10.1523/JNEUROSCI.0877-06.2006

Copyright $\odot 2006$ Society for Neuroscience $\quad$ 0270-6474/06/269069-07\$15.00/0
(Sladek and Johnson, 1983; Thrasher and Keil, 1987), whereas local osmotic stimulation of the area of the OVLT elicits osmoregulatory responses in water-replete animals (Andersson, 1971; Buggy et al., 1979). Although electrophysiological recordings in vivo (Honda et al., 1990) and in vitro (Sayer et al., 1984; Vivas et al., 1990; Nissen et al., 1993) have shown that OVLT neurons are excited by hypertonic stimuli, the functional basis for this osmoresponsiveness remains unknown.

Recent experiments have proposed various homologs of the mammalian transient receptor potential vanilloid (TRPV) family of cation channels as candidate osmosensory transducers (Liedtke and Kim, 2005). For example, homomultimeric channels formed by heterologous expression of mammalian TRPV2 (Muraki et al., 2003) or TRPV4 (Liedtke et al., 2000; Strotmann et al., 2000; Wissenbach et al., 2000) can be activated by hypoosmolality. Interestingly, a recent study has revealed that TRPV1 knock-out $\left(T R P V 1^{-/-}\right)$mice show impaired vasopressin release in response to a hypertonic challenge. Moreover, the intrinsic excitatory responses evoked by hyperosmotic stimuli in vasopressin-releasing neurons were absent in $T R P V 1^{-/-}$animals, suggesting that TRPV1 may contribute to the formation of a cation channel activated by hypertonicity (Sharif Naeini et al., 2006).

As indicated above, the mechanism that underlies the osmoresponsiveness of OVLT neurons is unknown. Specifically, it is not known whether these neurons are intrinsically osmosensitive 
or whether the effects of osmotic perturbations are mediated indirectly. Indeed, hyperosmolality could provoke excitation through the depolarizing effect of hypertonicity-activated cation channels expressed in the OVLT neurons themselves, as found in vasopressin-releasing neurons of the supraoptic nucleus (Oliet and Bourque, 1993; Bourque et al., 1994). Alternatively, increases in osmolality might turn off basally active hypotonicity-activated channels expressed in a neighboring cell, thereby provoking its hyperpolarization and suppressing the release of an inhibitory substance onto OVLT neurons (Mizuno et al., 2003). In this study, we used electrophysiological approaches to determine whether OVLT neurons are intrinsically sensitive to hypertonic stimuli. Because such a response would likely involve the expression of a hypertonicity-activated cation channel, we compared the effects of osmotic stimuli on OVLT neurons obtained from wild-type (WT) and TRPV1 ${ }^{-/-}$mice.

\section{Materials and Methods}

Extracellular recordings from hypothalamic explants. C57BL and $T R P V 1^{-1-}$ mice from the same background, 6-8 weeks of age, were anesthetized using halothane and decapitated, and the brains were removed rapidly according to a procedure approved by the McGill University Animal Care Committee. A block of tissue $5 \times 5 \times 2 \mathrm{~mm}$ containing the optic chiasm and the OVLT was excised using razor blades and pinned, ventral surface up, to the Sylgard base of a superfusion chamber. Within 3-5 min from decapitation, the excised OVLT explant was superfused (at $1.5 \mathrm{ml} / \mathrm{min}$ at $32-33^{\circ} \mathrm{C}$ ) with carbogenated ( $95 \%$ oxygen, $5 \%$ $\mathrm{CO}_{2}$ ) artificial CSF (ACSF) delivered via a Tygon tube placed over the rostral pole of the preparation. The optic nerves were removed to provide direct access to the OVLT, and a cotton wick was placed at the caudal tip of the explant to minimize the level of fluid over the preparation and to facilitate the removal of ACSF. The ACSF, $\mathrm{pH} 7.4$, contained the following (in mM): $125 \mathrm{NaCl}, 26 \mathrm{NaHCO}_{3}, 5 \mathrm{KCl}, 1.5 \mathrm{MgCl}_{2}, 1 \mathrm{CaCl}_{2}$, and 10 D-glucose. Mannitol was added to adjust the basal osmolality of the solution to $312 \pm 2 \mathrm{mOsm} / \mathrm{kg}$ or to make hypertonic solutions. Extracellular recordings were made from OVLT neurons using microelectrodes filled with $1 \mathrm{~m}$ potassium acetate (resistance of 5-10 M $\Omega$ ), and hyperosmotic stimuli were bath applied by switching the solution being delivered through the Tygon tube. For the analysis of changes in firing rate, the average rate of spike discharge of the neuron measured during the final minute of an osmotic stimulus was subtracted from the average firing rate observed before the onset of the stimulus.

Whole-cell recordings from acutely isolated OVLT neurons. To obtain acutely isolated OVLT neurons, blocks of tissue containing the OVLT $\left(<1 \mathrm{~mm}^{3}\right)$ were dissected from the brains of anesthetized C57BL or TRPV1 ${ }^{-1-}$ mice (6-8 weeks old) and incubated in oxygenated $(100 \%$ $\mathrm{O}_{2}$ ) PIPES solution containing the following: $120 \mathrm{~mm} \mathrm{NaCl}, 5 \mathrm{~mm} \mathrm{KCl}, 1$ $\mathrm{mm} \mathrm{MgCl}_{2}, 20 \mathrm{~mm}$ PIPES, $1 \mathrm{~mm} \mathrm{CaCl}_{2}, 10 \mathrm{~mm}$ D-glucose, $\mathrm{pH}$ 7.3, 0.5 $\mathrm{mg} / \mathrm{ml}$ Protease-X, and $0.5 \mathrm{mg} / \mathrm{ml}$ Protease-XIV at room temperature for $30 \mathrm{~min}$. Individual tissue blocks in enzyme-free PIPES solution were triturated, and the resulting suspension was plated onto Petri dishes. Cells were perfused $(1.2 \mathrm{ml} / \mathrm{min})$ with HEPES solution containing the following (in mM): $150 \mathrm{NaCl}, 3 \mathrm{KCl}, 1 \mathrm{MgCl}_{2}, 10 \mathrm{HEPES}, 1 \mathrm{CaCl}_{2}$, and 10 D-glucose, $\mathrm{pH} 7.3$, through one of the adjacent barrels of a three-channel glass capillary tube assembly. Mannitol was added to adjust the basal osmolality of the solution to $312 \pm 2 \mathrm{mOsm} / \mathrm{kg}$ or to make hypertonic solutions. Glass pipettes (1 mm outer diameter) were pulled on a Flaming-Brown puller (Sutter Instruments, Novato, CA) and filled with an internal solution ( $\mathrm{pH}$ 7.25) containing the following (in mM): 120 K-gluconate, $1 \mathrm{MgCl}_{2}$, 1 EGTA, $4 \mathrm{Na}_{2} \mathrm{ATP}, 1 \mathrm{NaGTP}, 14$ phosphocreatine, and 10 HEPES. Cells were patch clamped in the whole-cell currentclamp and voltage-clamp modes using an Axopatch-1D amplifier (Molecular Devices, Sunnyvale, CA). In the current-clamp experiments, cells were deemed responsive to hypertonic stimuli if they displayed a membrane depolarization $>2 \mathrm{mV}$ and increases in firing rate $>15 \% \mathrm{com}$ pared with control. In the voltage-clamp experiments, $0.5 \mu \mathrm{M}$ tetrodotoxin (TTX) was added to the HEPES solution to block voltage-gated sodium channels. In both conditions, hyperosmotic stimuli were applied by switching the channel of the delivery tube assembly to one containing hyperosmotic HEPES using a piezoelectric stepper device (SF-77B; Warner Instruments, Hamden, CT). The TRPV channel blocker ruthenium red (RR) was used at a concentration of $10 \mu \mathrm{M}$ in the perfusion solution. Gadolinium was diluted from a stock concentration of $30 \mathrm{~mm}$ in water to the final concentration of $300 \mu \mathrm{M}$ in the perfusing solution. In all experiments, the overflow solution was sucked away via a vacuum system.

Volume measurements. We quantified percentage changes in cell volume from measurements of maximal cross-sectional area (CSA) (from digitized video images) of the cell using Scion Image for Windows 4.02 (Scion, Frederick, MD) as performed previously (Oliet and Bourque, 1993). All values of CSA measured in the control period were averaged $\left(\mathrm{CSA}_{\mathrm{o}}\right)$, and values of normalized volume at individual time points $\left(\mathrm{nV}_{\mathrm{t}}\right)$ were calculated from the CSA value at that time point $\left(\mathrm{CSA}_{\mathrm{t}}\right)$ using the following equation: $\mathrm{nV}_{\mathrm{t}}=\left[\left(\mathrm{CSA}_{\mathrm{t}}\right)^{1.5} /\left(\mathrm{CSA}_{\mathrm{o}}\right)^{1.5}\right]$. Percentage changes in volume $(\Delta \mathrm{V} \%)$ were calculated as $\Delta \mathrm{V} \%=\left(1-\mathrm{nV}_{\mathrm{t}}\right) \times 100$.

Water intake measurements in mice. Age-matched WT and TRPV1 ${ }^{-1-}$ mice housed in individual cages were injected intraperitoneally with hypertonic $(1 \mathrm{M} \mathrm{NaCl})$ or isotonic $(150 \mathrm{~mm} \mathrm{NaCl})$ solution at a dose of 10 $\mu \mathrm{l} / \mathrm{g}$ body weight. Water and food were removed at this point. After 30 min, water was reintroduced in the cages, and the amount of water consumed (per gram of body weight) during a $30 \mathrm{~min}$ period was determined.

Statistics. All values are reported as mean \pm SE. Comparisons of the means between groups were made using a paired $t$ test or a two-way ANOVA (SigmaStat 2.1; Systat Software, Port Richmond, CA), as appropriate. Differences between the means were considered significant when $p<0.05$. When differences were found, the Student-Newman-Keuls test for multiple comparisons was performed post hoc to identify specific distinctions $(p<0.05)$. Slopes of linear regressions were compared using Prism 4.03 (GraphPad Software, San Diego, CA).

\section{Results}

\section{Osmosensitivity of OVLT neurons in hypothalamic explants}

We first investigated the possible involvement of the trpv1 gene in the osmotic control of OVLT neurons by comparing the effects of hypertonic stimulation on the electrical activity of these cells in superfused hypothalamic explants obtained from adult WT and $T R P V 1^{-/-}$mice. Increasing the osmolality of the external solution by the addition of mannitol caused reversible increases in the firing rate of many WT OVLT neurons (Fig. $1 A$ ). As illustrated in Figure $1 B$, this increase in firing rate was proportional to the magnitude of the osmotic stimulus, and linear regression analysis of the data revealed that firing rate in the population as a whole increased at a rate of $+0.047 \mathrm{~Hz} \cdot \mathrm{mOsm}^{-1} \cdot \mathrm{kg}^{-1}(r=0.56 ; p<$ $0.0001 ; n=128)$. In contrast, OVLT neurons recorded from hypothalamic explants prepared from age-matched TRPV1 ${ }^{-/-}$ mice consistently failed to respond to osmotic stimulation (Fig. $1 C$ ). Indeed, regression analysis (Fig. 1D) revealed that the slope of the relationship between changes in firing rate and osmolality observed in these cells (slope of $0.003 \mathrm{~Hz} \cdot \mathrm{mOsm}^{-1} \cdot \mathrm{kg}^{-1} ; r=$ $0.12 ; n=62)$ was not significantly different from $0(p=0.35)$. To estimate the true sensitivity of the subset of WT OVLT neurons that are osmoresponsive, we next separated WT cells according to the magnitude of their response to osmotic stimulation. Because the overall SD of changes in firing rate measured in (nonosmoresponsive) OVLT neurons from $T R P V 1^{-/-}$mice was $\pm 0.48 \mathrm{~Hz}$, WT OVLT neurons showing responses greater than this value were considered to be osmoresponsive, whereas cells showing changes in firing rate smaller than this value were considered to be non-osmosensitive. Based on this analysis, 63\% (40 of 64) of the WT OVLT neurons we sampled were deemed to be osmoresponsive, and the sensitivity of these particular cells was $+0.07 \mathrm{~Hz} \cdot \mathrm{mOsm}^{-1} \cdot \mathrm{kg}^{-1}(r=0.72 ; n=80)$. As expected, 
A
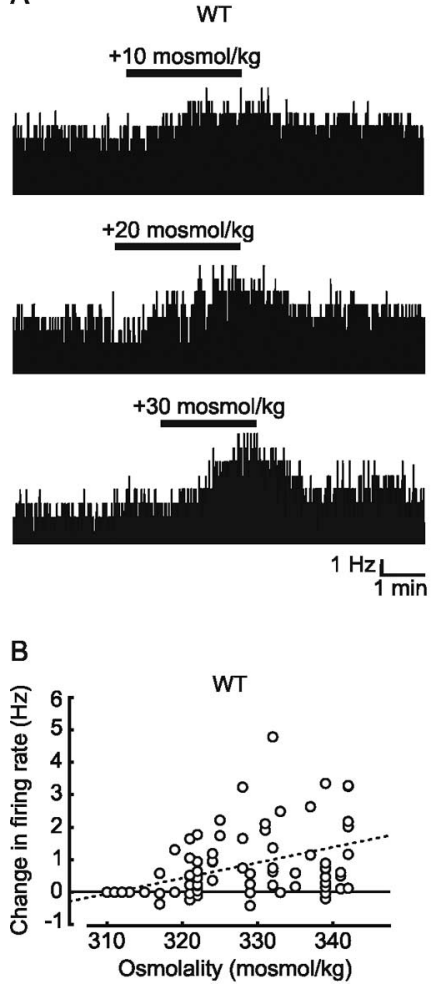

C
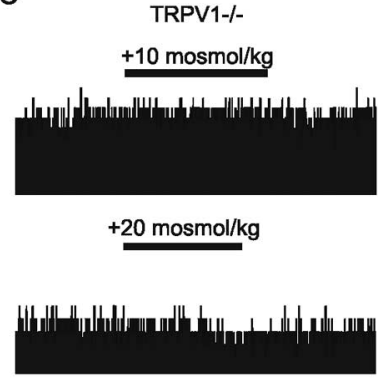

$+30 \mathrm{mosmol} / \mathrm{kg}$

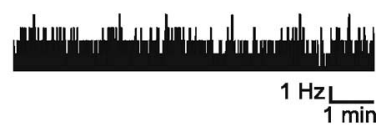

$\mathrm{D}$

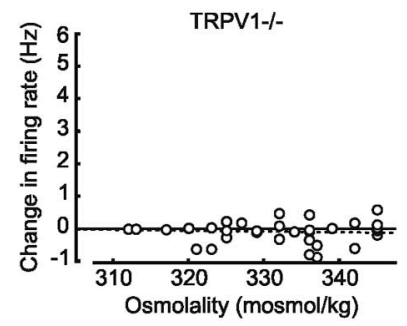

A
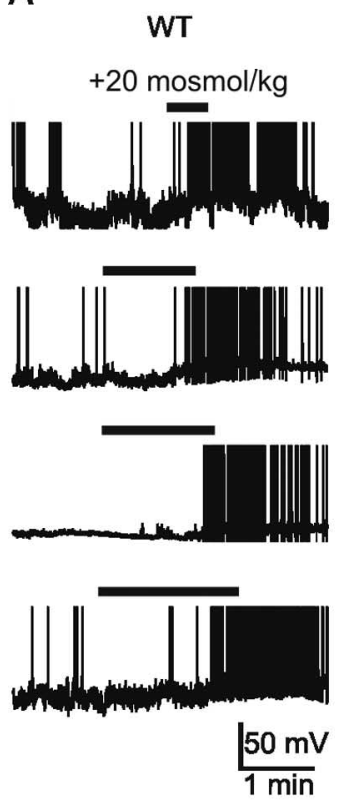

B

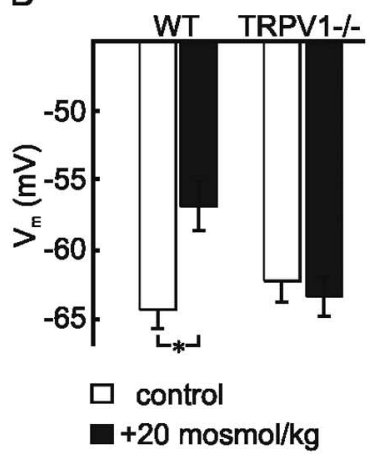

TRPV1-I-
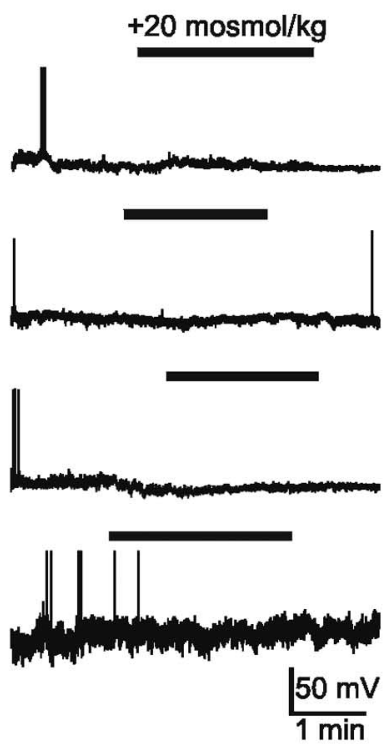

C

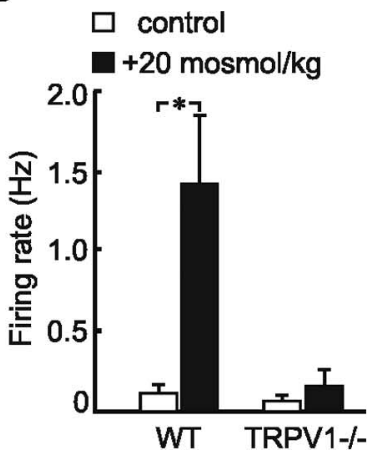

Figure 1. Extracellular recordings from OVLT neurons in hypothalamic explants. $A$, Representative examples of extracellular recordings obtained from different osmoresponsive OVLT neurons in acute hypothalamic explants prepared from WT mice. Note the reversible increases in firing rate observed in response to hypertonic stimulation (bar). B, Scatter plot analysis of the changes in firing rate evoked by hypertonic stimuli in the whole population of WT OVLT neurons sampled. For each trial, two points are plotted: one corresponding to the basal state (i.e., $\Delta \mathrm{Hz}=0$ at $312 \pm 2 \mathrm{~m} 0 \mathrm{sm} / \mathrm{kg}$ ) and one plotting the change in rate observed in response to the particular osmotic stimulus. The dashed line is a linear regression fit to the data points. Note that many but not all cells are osmoresponsive. C, Representative examples of extracellular recordings obtained from different OVLT neurons during osmotic stimulation (bars) in explants prepared from TRPV1 ${ }^{-1-}$ mice. D, Scatter plot analysis of the changes in firing rate evoked by hypertonic stimuli in all of the TRPV1 ${ }^{-1-}$ OVLT neurons sampled. In this case, the slope of the linear regression fit (dashed line) is not significantly different from 0 , indicating a lack of osmoresponsiveness.

there was no relationship between changes in firing rate and osmolality in the group of OVLT cells identified as nonosmosensitive (slope of $0.005 \mathrm{~Hz} \cdot \mathrm{mOsm}^{-1} \cdot \mathrm{kg}^{-1} ; r=0.29 ; n=$ 48). These findings suggest that a majority of OVLT neurons are osmoresponsive and that a product of the trpvl gene is required for expression of this phenotype in situ.

\section{OVLT neurons are intrinsically osmosensitive}

The excitatory effects of hypertonicity observed in OVLT neurons in explants obtained from WT mice could reflect an intrinsic osmosensitivity of these neurons or an indirect osmoresponsiveness mediated by substances released by adjacent non-neuronal cells or by synaptic afferents originating from neurons in other nuclei. To determine whether OVLT neurons are intrinsically osmosensitive, we therefore examined the effects of hyperosmotic stimulation on neurons acutely isolated from the OVLT of adult WT mice. Under whole-cell current-clamp conditions, a hypertonic stimulus of $+20 \mathrm{mOsm} / \mathrm{kg}$ caused a mean depolarization of the WT OVLT neurons from $-64.3 \pm 1.3$ to $-56.9 \pm$ $1.8 \mathrm{mV}\left(n=36 ; p=1.01 \times 10^{-5}\right)$ (Fig. $\left.2 A, B\right)$. In addition, this effect was associated with a significant increase in the firing rate of

Figure 2. Current-clamp analysis of osmotically stimulated OVLT neurons. A, Representative examples of current-clamp recordings from osmotically stimulated (bar) OVLT neurons acutely isolated from WT (left column) and TRPV1 ${ }^{-1-}$ (right column) mice. Note that hypertonic stimuli consistently depolarize and excite WT but not TRPV1 ${ }^{-/-}$neurons. $B$, Bar graphs show the mean \pm SE membrane potential $\left(V_{m}\right)$ observed under control and osmotically stimulated conditions in OVLT neurons from WT and TRPV1 ${ }^{-/-}$mice. Note that no significant depolarization was observed in neurons from $T R P V 1^{-1-}$ mice. C, Bar graphs show the mean \pm SE changes in firing rate observed under control and osmotically stimulated conditions in OVLT neurons from WT and TRPV $1^{-1-}$ mice. Note the absence of osmotically induced excitation in neurons from TRPV1 $^{-1-}$ mice. ${ }^{*} p<0.005$

the cells from $0.11 \pm 0.05$ to $1.43 \pm 0.42 \mathrm{~Hz}(n=36 ; p=0.002)$ (Fig. 2C). Indeed, when considering the entire population of responsive neurons $(>61 \%)$, the increase in firing rate observed during osmotic stimulation was positively correlated with the amplitude of the depolarization (slope of $0.26 \mathrm{~Hz} / \mathrm{mV} ; r=0.69$; data not shown), indicating that the magnitude of the osmoreceptor potential determines the degree of excitation under these conditions. These findings reveal that a population of OVLT neurons has the intrinsic ability to transduce hyperosmotic stimuli into depolarizing receptor potentials that generate proportional increases in the rate of action potential discharge. To determine whether the trpvl gene contributes to the intrinsic osmosensitivity of OVLT neurons, we repeated the same test on neurons isolated from the OVLT of age-matched TRPV1 ${ }^{-1-}$ mice. As illustrated in Figure $2 A$, hyperosmotic stimuli failed to affect the membrane potential (from $-62.2 \pm 1.6$ to $-63.4 \pm 1.4 \mathrm{mV} ; n=$ 
A

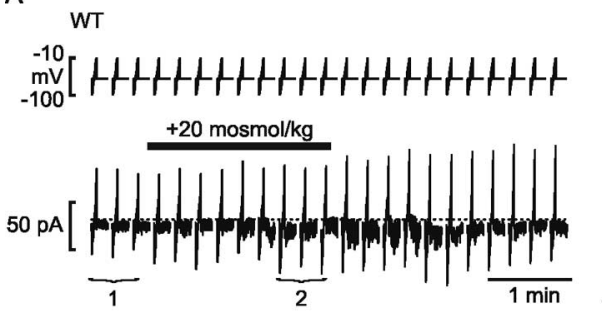

B

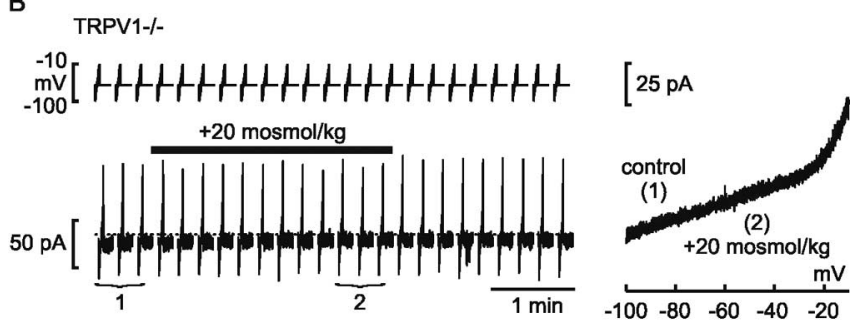

C

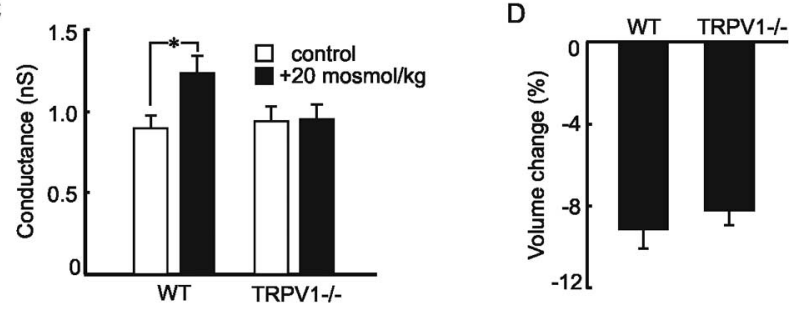

Figure 3. Voltage-clamp analysis of osmotically stimulated OVLT neurons. $\boldsymbol{A}$, Representative example of a whole-cell voltage-clamp recording obtained from a WT OVLT neuron (left). The bottom trace shows current responses to voltage ramp commands ( $27 \mathrm{mV} / \mathrm{s}$; top) from -100 to $-10 \mathrm{mV}$ applied every $15 \mathrm{~s}$ before, during (bar), and after the delivery of an osmotic stimulus. Note the appearance of a reversible inward current (compared with dotted line) in response to the hypertonic stimulus. The right shows steady-state $/-V$ relationships obtained by averaging current responses to three consecutive voltage ramps applied under control conditions (1) and during osmotic stimulation (2), as indicated in the left trace. Note the increase in slope of the $I-V$ relationship under hypertonic conditions. $\boldsymbol{B}, A$ representative example of a similar experiment performed on an OVLT neuron from a TRPV1 ${ }^{-1-}$ mouse. Note the absence of a change in holding current (left) or slope of the $I-V$ relationship (right) during hypertonic stimulation. C, Bar graphs show the mean \pm SE changes in membrane conductance (slope of $I-V$ relationships) observed under control and osmotically stimulated conditions in OVLT neurons from WT and $T R P V 1^{-1-}$ mice. Note the absence of osmotically induced conductance increase in neurons from TRPV1 ${ }^{-/-}$mice. ${ }^{*} p<0.001$. D, Bar graphs showing the mean $\pm \mathrm{SE}$ maximum percentage changes in cell volume observed during hypertonic stimulation in isolated OVLT neurons from WT and TRPV1 ${ }^{-/-}$mice.

$20 ; p=0.4)$ (Fig. $2 B$ ) or the firing rate of $T R P V 1^{-/-}$neurons (from $0.07 \pm 0.04$ to $0.15 \pm 0.10 \mathrm{~Hz} ; n=20 ; p=0.21$ ) (Fig. $2 C$ ). Together, these data indicate that OVLT neurons are intrinsically osmosensitive and suggest that the presence of a product of the trpvl gene is necessary for osmosensory transduction.

\section{Osmosensory transduction involves hypertonicity-activated cation channels}

If a channel comprising TRPV1 protein operates as the osmosensory transduction channel, then the depolarizing and excitatory responses to hypertonicity should be caused by an inward current associated with an increase in membrane cation conductance. We therefore investigated this issue by performing steady-state current-voltage $(I-V)$ analysis on isolated WT OVLT neurons under whole-cell voltage clamp in the presence of TTX. In cells clamped at a holding voltage near resting potential $(-60 \mathrm{mV})$, bath application of a hypertonic stimulus caused a reversible inward current (Fig. 3A). Moreover, steady-state $I-V$ relationships measured every $15 \mathrm{~s}$ revealed that the amplitude of this inward current was associated with a proportional increase in membrane conductance, confirming that ion channels are activated under these conditions. The mean reversal potential of the osmotically evoked current was $-27.6 \pm 4.5 \mathrm{mV}$, consistent with the involvement of nonselective cation channels under our experimental conditions (see Discussion). Additionally, increases in membrane conductance induced by hyperosmolality could be reversed by bath application of $300 \mu \mathrm{M} \mathrm{Gd}^{3+}(\Delta G=0.51 \pm 0.15 \mathrm{nS}$ before and $\Delta G=-0.16 \pm 0.06 \mathrm{nS}$ after $\mathrm{Gd}^{3+} ; n=8 ; p=0.003$; data not shown), a blocker of nonselective cation channels (Hase et al., 1995; Cho et al., 2002).

\section{OVLT neurons from $T R P V 1^{-/-}$mice fail to transduce osmotic stimuli}

To determine whether the presence of TRPV1 is required for the conductance increase and activation of an inward current, we examined the effects of hypertonic stimuli on voltage-clamped OVLT neurons from TRPV1 $1^{-1-}$ mice. As illustrated in Figure $3 B$, OVLT neurons from TRPV1 $1^{-/-}$animals failed to show detectable changes in holding current or membrane conductance on exposure to hypertonicity. Whereas the membrane conductance of WT OVLT neurons increased significantly during the hypertonic stimulation (from $0.91 \pm 0.08$ to $1.24 \pm 0.12 \mathrm{nS} ; n=38$; $p=1.56 \times 10^{-5}$ ), OVLT neurons isolated from $T R P V 1^{-/-}$mice showed no significant changes in conductance in response to the same stimulus (control, $0.94 \pm 0.09$ vs $0.95 \pm 0.09 \mathrm{nS}$ during hypertonicity; $n=23 ; p=0.7$ ) (Fig. $3 C$ ).

Because changes in cell volume are hypothesized to participate in osmosensory transduction (Oliet and Bourque, 1993; Hussy et al., 2000), we also compared the degree of volume change induced by hypertonic stimulation in OVLT neurons isolated from WT and TRPV1 ${ }^{-1-}$ mice. As shown in Figure $3 D$, no significant difference was observed between the two strains, indicating that the absence of osmotically induced responses in OVLT neurons of TRPV1 ${ }^{-/-}$mice is not attributable to an alteration of the effect of osmotic stimulation on cell volume.

\section{Osmosensory transduction is blocked by ruthenium red}

The data presented so far show that cation channels transduce hyperosmotic stimuli into conductance increases and depolarizing receptor potentials to excite WT OVLT neurons, and such effects are lost in TRPV1 $1^{-/-}$mice. If a product of the trp 1 gene is a functional component of the osmosensory transduction channel, then responses to hypertonicity should be inhibited by RR, a generic blocker of TRPV channels (Watanabe et al., 2003). As illustrated in Figure $4 A$, the presence of $2 \mu \mathrm{M}$ RR abolished the conductance increase induced by hypertonic stimulation in isolated WT OVLT neurons. Under control conditions, the membrane conductance of OVLT neurons increased (from $0.87 \pm$ 0.12 to $1.14 \pm 0.16 \mathrm{nS} ; n=19 ; p=0.005)$, whereas RR-treated cells failed to show a significant change (from $0.67 \pm 0.07$ to $0.70 \pm 0.14 \mathrm{nS} ; n=8 ; p=0.8$ ) (Fig. $4 B$ ).

\section{TRPV1 contributes to osmotic thirst in vivo}

Because the osmotic activation of OVLT neurons is believed to contribute to the generation of thirst (Thrasher, 1989; McKinley et al., 2004a,b), we hypothesized that $T R P V 1^{-/-}$mice would show deficits in drinking behavior after a systemic hypertonic challenge. To examine this hypothesis, access to water was removed for a period of $30 \mathrm{~min}$ after a single intraperitoneal injection $(10 \mathrm{ml} / \mathrm{kg}$ body weight $)$ of either saline $(0.15 \mathrm{M} \mathrm{NaCl})$ or hypertonic solution $(1 \mathrm{M} \mathrm{NaCl})$. Analysis performed on separate 
A

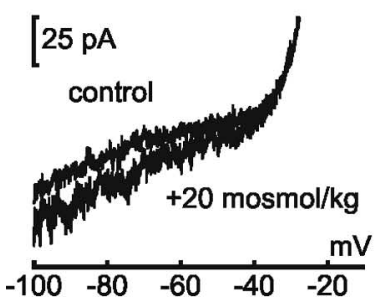

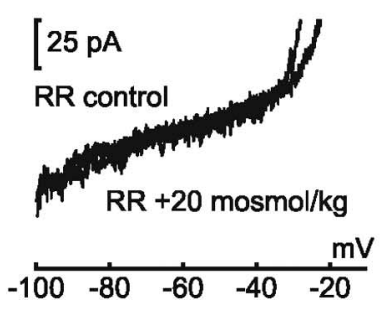

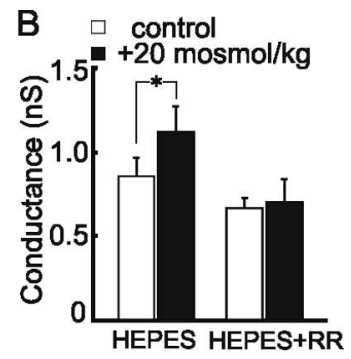

Figure 4. Ruthenium red blocks osmosensory transduction in WT OVLT neurons. $\boldsymbol{A}$, Top, Shows steady-state $/-V$ relationships recorded from an isolated WT OVLT neuron under control and hypertonic ( $+20 \mathrm{m0sm} / \mathrm{kg}$ ) conditions. Bottom, $I-V$ relationships recorded under the same conditions, from the same cell, but in the presence of $10 \mu \mathrm{m}$ RR. Note that RR blocks the conductance increase induced by hypertonicity. $\boldsymbol{B}$, Bar graphs show mean \pm SE values of membrane conductance observed before and during hypertonic stimulation in the absence (HEPES, left) and presence (HEPES $+\mathrm{RR}$, right) of RR. ${ }^{*} p<0.01$. animals revealed that injection of the hypertonic solution caused an equivalent increase in serum osmolality in both $\mathrm{WT}(+15.8 \pm$ $1.7 \mathrm{mOsm} / \mathrm{kg} ; n=8)$ and TRPV1 ${ }^{-1-}(+15.2 \pm 1.9 \mathrm{mOsm} / \mathrm{kg}$; $n=10)$ mice compared with genetically matched saline-injected controls ( $p=0.827$ ), a stimulus sufficient to motivate drinking in most mammals (Thrasher et al., 1982; Egan et al., 2003). Indeed, during the first $30 \mathrm{~min}$ after the reintroduction of water, osmotically stimulated WT mice drank significantly more per unit body weight $(30.7 \pm 2.05 \mu \mathrm{l} / \mathrm{g})$ than saline-injected controls $\left(5.3 \pm 1.2 \mu \mathrm{l} / \mathrm{g} ; p=3.3 \times 10^{-8}\right)$. The same test performed in TRPV1 $1^{-/-}$mice also evoked drinking in these animals $(23.4 \pm$ $2.1 \mu \mathrm{l} / \mathrm{g}$ in hypertonic vs $7.9 \pm 1.9 \mu \mathrm{l} / \mathrm{g}$ in control; $p=5.5 \times$ $\left.10^{-5}\right)$. However, osmotically challenged $T R P V 1^{-1-}$ mice ingested significantly less water than WT animals $(p=0.02)$. Thus, a product of the trpv1 gene contributes to the generation of thirst in response to systemic hypertonicity.

\section{Discussion}

\section{The OVLT is a primary homeostatic osmosensory nucleus}

Pioneering experiments by Andersson et al. (1975) first demonstrated the importance of the anterior wall of the third ventricle in the generation of thirst $>30$ years ago. Studies combining systemic infusions, intracerebroventricular injection, and fluid sampling, along with neuroendocrine and behavioral analysis, subsequently established that an increase in the osmotic pressure of the CSF is sufficient to induce thirst and vasopressin release in unanesthetized animals (Andersson, 1971; McKinley et al., 1978; Buggy et al., 1979; Thrasher et al., 1980). Lesion studies performed in vivo and in vitro ultimately localized the primary homeostatic osmosensory area to the OVLT, a small circumventricular organ that borders the dorsal aspect of the preoptic recess of the third ventricle (McKinley et al., 1982; Thrasher et al., 1982; Sladek and Johnson, 1983). Indeed, damage to brain areas encompassing the OVLT in humans causes diabetes insipidus as a result of an absence of osmotically regulated vasopressin release and chronic hypernatremia attributable to adipsia (Rudelli and Deck, 1979; Kubota et al., 1991).

\section{OVLT neurons are intrinsically osmosensitive}

Previous studies have shown that infusion of hypertonic solutions into the OVLT area triggers drinking and antidiuresis in awake, water-satiated animals (Andersson, 1971; Buggy et al., 1979). Moreover, hypertonic stimuli have been shown to activate a proportion of OVLT neurons as revealed by increased Fos immunolabeling (Oldfield et al., 1991; McKinley et al., 1994; Xu and Herbert, 1995) and by electrophysiological recordings in in vitro brain slices (Vivas et al., 1990) or explants (Nissen et al., 1993).
Although these observations suggest that hypertonicity-induced excitation of OVLT neurons is essential for systemic osmoregulation, definitive evidence indicating that these cells are intrinsically osmosensitive has been lacking. Indeed, although hypertonic $\mathrm{NaCl}$ can elicit excitatory responses from OVLT neurons in brain slices even when they are perfused with low $\mathrm{Ca}^{2+}$ solutions to block synaptic transmission (Vivas et al., 1990), such experiments do not exclude a possible role for substances released from nonneuronal osmosensory cells or the involvement of $\mathrm{Na}^{+}$receptors rather than osmoreceptors. Indeed, recent studies have demonstrated that osmotically regulated taurine release by glial cells can contribute to neuronal osmoresponsiveness through the activation of glycine receptors (Hussy, 2002), and subpopulations of neurons in the lamina terminalis have been shown to be specifically sensitive to changes in sodium concentration rather than osmolality (Grob et al., 2004). Our finding that isolated OVLT neurons respond to solutions made hypertonic via the addition of mannitol therefore provide the first direct evidence that a large proportion of these cells are intrinsically osmosensitive.

\section{Ionic basis for osmoreception in OVLT neurons}

Several ionic mechanisms could hypothetically mediate an inward current and neuronal excitation under hypertonic conditions. Specifically, hypertonicity could induce membrane depolarization by either inhibiting ion channels that have an equilibrium potential $\left(E_{\mathrm{rev}}\right)$ more negative than the resting membrane potential (Abe and Ogata, 1982) or opening channels that have an $E_{\text {rev }}$ more positive than the resting potential (Oliet and Bourque, 1993). The first mechanism can be excluded here because depolarizing osmoreceptor potentials were associated with channel opening, as indicated by the increased membrane conductance observed under hypertonic conditions. Moreover, under our recording conditions, the Nernst potentials for $\mathrm{K}^{+}(-88$ $\mathrm{mV})$ and $\mathrm{Cl}^{-}(-125 \mathrm{mV})$ ions were both more negative than the resting potential. Thus, channels selectively permeable to either of these ions could not have mediated osmosensory transduction. Because the $E_{\mathrm{rev}}$ of the osmotically evoked current lies between the equilibrium potentials for $\mathrm{K}^{+}$and $\mathrm{Na}^{+}(+84 \mathrm{mV})$ ions, it is likely that nonselective cation channels mediate osmoreception in OVLT neurons. In support of this hypothesis, bath application of $\mathrm{Gd}^{3+}$, a blocker of nonselective cation channels (Hase et al., 1995; Cho et al., 2002), suppressed the effects of hypertonic stimulation on OVLT neurons.

\section{Expression of the trpv1 gene is required for osmoreception in OVLT neurons}

Recently, the search for molecular components responsible for osmotic detection has brought attention to the TRPV family of cationic channels (Liedtke and Kim, 2005; O'Neil and Heller, 2005). For example, mice lacking TRPV1 (Sharif Naeini et al., 2006) or TRPV4 (Liedtke and Friedman, 2003; Mizuno et al., 2003) have been found to display impaired osmoregulatory responses to systemic hypertonicity. Moreover, hypo-osmotic solutions can activate heterologously expressed channels composed of homomultimers of TRPV2 (Muraki et al., 2003) or TRPV4 (Liedtke et al., 2000; Strotmann et al., 2000; Wissenbach et al., 
2000). Although heterologously expressed homomultimers comprising the native capsaicin receptor (i.e., TRPV1) do not respond to hypotonicity (Liedtke et al., 2000), a recent study has suggested that a capsaicin-insensitive $\mathrm{N}$-terminal splice variant of TRPV1 may contribute to the formation of a hypertonicityactivated cation channel in vasopressin-releasing neurons of the supraoptic nucleus (Sharif Naeini et al., 2006). Because the cation channel mediating osmosensory transduction in OVLT neurons is also activated by hypertonicity, we examined whether responses to hypertonicity were affected in TRPV1 $1^{-/-}$mice. Our findings show unequivocally that a product of the trpv1 gene is required for osmosensitivity in the primary osmosensory neurons of the OVLT.

Hypothetically, the osmosensory deficit of OVLT neurons in TRPV1 ${ }^{-/-}$mice could be attributable to a developmental defect. However, TRPV1 ${ }^{-/-}$mice display no gross neuroanatomical abnormalities, and the density of cells expressing the neuronal marker neuronal-specific nuclear protein was equivalent in the OVLT of WT and TRPV1 ${ }^{-1-}$ animals (our unpublished observations). A more likely possibility is that a product of the trpv1 gene plays a functional role as a pore-forming channel in the osmosensory transduction complex of OVLT neurons. In support of this hypothesis, we found that the osmosensory transduction current can be blocked by RR, a generic blocker of TRPV channels (Watanabe et al., 2003). Although additional work will be required to determine the precise molecular nature of the osmosensory transduction channel in OVLT neurons, preliminary analysis indicates that these cells are insensitive to capsaicin (our unpublished observations), suggesting that a splice variant of TRPV1 may contribute to the osmosensitivity of these cells, as shown recently for supraoptic nucleus neurons (Sharif Naeini et al., 2006).

\section{Impaired osmotic thirst in TRPV1 ${ }^{-/-}$mice}

The involvement of the $\operatorname{trp} v 1$ gene in systemic osmoregulation was first indicated in a report showing that TRPV1 $1^{-/-}$mice display a significantly elevated basal plasma osmolality, a lack of intrinsic osmosensitivity in supraoptic nucleus neurons, and impaired vasopressin release in response to a systemic hypertonic challenge (Sharif Naeini et al., 2006). Although the intrinsic osmosensitivity of supraoptic nucleus neurons is important for the osmotic control of vasopressin release, these cells do not share osmosensory information with other parts of the brain and are unlikely to modulate other CNS-dependent osmoregulatory responses because they project exclusively to the posterior pituitary (Bourque et al., 1994). In contrast, OVLT neurons are extensively interconnected with other nuclei implicated in the control of hydromineral balance, and their activation is believed to be a key step in the activation and coordination of most osmoregulatory responses, including thirst (Thrasher, 1989; McKinley et al., 2004). Because a product of the trpvl gene is required for the intrinsic osmosensitivity of OVLT neurons, we compared the effects of a systemic hypertonic challenge on the drinking responses of WT and TRPV1 $1^{-/-}$mice. Mutant mice showed a significantly attenuated response when compared with WT counterparts, confirming a role for the trpv1 gene in osmotically driven thirst. Interestingly, intraperitoneal injections of hypertonic saline still evoked a significant drinking response in the TRPV1 $1^{-/-}$animals. This residual response could have been mediated by a variety of factors. First, although hypertonic stimuli failed to excite isolated OVLT neurons and OVLT neurons in hypothalamic explants, it is possible that additional mechanisms contribute to the osmotic activation of these cells in vivo and thus mediate partial drinking responses in $T R P V 1^{-/-}$mice. A second possibility is that CNS areas other than the OVLT can contribute to the osmotic modulation of thirst. Indeed, osmosensitive and $\mathrm{Na}^{+}$-sensitive neurons have been found in the subfornical organ (Anderson et al., 2001) and in the median preoptic nucleus (McAllen et al., 1990; Travis and Johnson, 1993; Grob et al., 2004), areas known to be part of the integrated neural circuit that underlies osmoregulation (Johnson and Gross, 1993). Finally, it is possible that our protocol did not lead to a pure osmotic stimulus and that additional (i.e., non-osmotic) factors contributed to the thirst response. For example, intraperitoneal injection of hypertonic saline causes water to shift from the vascular compartment to the peritoneal cavity; it is therefore possible that the hypovolemia caused by such a stimulus could have induced part of the thirst response (Johnson and Thunhorst, 1997). Although additional studies will be required to define the mechanisms responsible for the residual drinking response in TRPV1 $1^{-1-}$ mice (and possibly for the nonlethality of this mutation), our data establish that the trpv1 gene is required for osmosensory transduction in OVLT neurons and provide support for the role of this process in the CNS control of systemic osmoregulation.

\section{References}

Abe H, Ogata N (1982) Ionic mechanism for the osmotically-induced depolarization in neurones of the guinea-pig supraoptic nucleus in vitro. J Physiol (Lond) 327:157-171.

Anderson JW, Smith PM, Ferguson AV (2001) Subfornical organ neurons projecting to paraventricular nucleus: whole-cell properties. Brain Res 921:78-85.

Andersson B (1971) Thirst and brain control of water balance. Am Sci 59:408-415.

Andersson B, Leksell LG, Lishajko F (1975) Perturbations in fluid balance induced by medially placed forebrain lesions. Brain Res 99:261-275.

Andersson B, Leksell LG, Rundgren M (1982) Regulation of water intake. Annu Rev Nutr 2:73-89.

Bealer SL, Phillips MI, Johnson AK, Schmid PG (1979) Anteroventral third ventricle lesions reduce antidiuretic responses to angiotensin II. Am J Physiol 236:E610-E615.

Bourque CW, Oliet SH, Richard D (1994) Osmoreceptors, osmoreception, and osmoregulation. Front Neuroendocrinol 15:231-274.

Buggy J, Johnson AK (1977) Preoptic-hypothalamic periventricular lesions: thirst deficits and hypernatremia. Am J Physiol 233:R44-R52.

Buggy J, Hoffman WE, Phillips MI, Fisher AE, Johnson AK (1979) Osmosensitivity of rat third ventricle and interactions with angiotensin. Am J Physiol 236:R75-R82.

Cho H, Shin J, Shin CY, Lee SY, Oh U (2002) Mechanosensitive ion channels in cultured sensory neurons of neonatal rats. J Neurosci 22:1238-1247.

Denton DA, McKinley MJ, Weisinger RS (1996) Hypothalamic integration of body fluid regulation. Proc Natl Acad Sci USA 93:7397-7404.

Egan G, Silk T, Zamarripa F, Williams J, Federico P, Cunnington R, Carabott L, Blair-West J, Shade R, McKinley M, Farrell M, Lancaster J, Jackson G, Fox P, Denton D (2003) Neural correlates of the emergence of consciousness of thirst. Proc Natl Acad Sci USA 100:15241-15246.

Grob M, Drolet G, Mouginot D (2004) Specific $\mathrm{Na}^{+}$sensors are functionally expressed in a neuronal population of the median preoptic nucleus of the rat. J Neurosci 24:3974-3984.

Hase CC, Le Dain AC, Martinac B (1995) Purification and functional reconstitution of the recombinant large mechanosensitive ion channel (MscL) of Escherichia coli. J Biol Chem 270:18329-18334.

Honda K, Negoro H, Dyball RE, Higuchi T, Takano S (1990) The osmoreceptor complex in the rat: evidence for interactions between the supraoptic and other diencephalic nuclei. J Physiol (Lond) 431:225-241.

Hussy N (2002) Glial cells in the hypothalamo-neurohypophysial system: key elements of the regulation of neuronal electrical and secretory activity. Prog Brain Res 139:95-112.

Hussy N, Deleuze C, Desarmenien MG, Moos FC (2000) Osmotic regulation of neuronal activity: a new role for taurine and glial cells in a hypothalamic neuroendocrine structure. Prog Neurobiol 62:113-134. 
Johnson AK, Gross PM (1993) Sensory circumventricular organs and brain homeostatic pathways. FASEB J 7:678-686.

Johnson AK, Thunhorst RL (1997) The neuroendocrinology of thirst and salt appetite: visceral sensory signals and mechanisms of central integration. Front Neuroendocrinol 18:292-353.

Kubota M, Shinozaki M, Ishizaki A, Kurata K (1991) Sodium regulation disorder, hypothermia, and circadian rhythm disturbances of the body temperature and sleep-wakefulness as sequelae of acute subdural hematoma [Japanese]. No To Shinkei 43:81-86.

Liedtke W, Friedman JM (2003) Abnormal osmotic regulation in trpv4 $4^{-1-}$ mice. Proc Natl Acad Sci USA 100:13698-13703.

Liedtke W, Kim C (2005) Functionality of the TRPV subfamily of TRP ion channels: add mechano-TRP and osmo-TRP to the lexicon! Cell Mol Life Sci 62:2985-3001.

Liedtke W, Choe Y, Marti-Renom MA, Bell AM, Denis CS, Sali A, Hudspeth AJ, Friedman JM, Heller S (2000) Vanilloid receptor-related osmotically activated channel (VR-OAC), a candidate vertebrate osmoreceptor. Cell 103:525-535.

McAllen RM, Pennington GL, McKinley MJ (1990) Osmoresponsive units in sheep median preoptic nucleus. Am J Physiol 259:R593-R600.

McKinley MJ, Denton DA, Weisinger RS (1978) Sensors for antidiuresis and thirst: osmoreceptors or CSF sodium detectors? Brain Res 141:89-103.

McKinley MJ, Denton DA, Leksell LG, Mouw DR, Scoggins BA, Smith MH, Weisinger RS, Wright RD (1982) Osmoregulatory thirst in sheep is disrupted by ablation of the anterior wall of the optic recess. Brain Res 236:210-215.

McKinley MJ, Hards DK, Oldfield BJ (1994) Identification of neural pathways activated in dehydrated rats by means of Fosimmunohistochemistry and neural tracing. Brain Res 653:305-314.

McKinley MJ, Gerstberger R, Mathai ML, Oldfield BJ, Schmid H (1999) The lamina terminalis and its role in fluid and electrolyte homeostasis. J Clin Neurosci 6:289-301.

McKinley MJ, Mathai ML, McAllen RM, McClear RC, Miselis RR, Pennington GL, Vivas L, Wade JD, Oldfield BJ (2004a) Vasopressin secretion: osmotic and hormonal regulation by the lamina terminalis. J Neuroendocrinol 16:340-347.

McKinley MJ, Cairns MJ, Denton DA, Egan G, Mathai ML, Uschakov A, Wade JD, Weisinger RS, Oldfield BJ (2004b) Physiological and pathophysiological influences on thirst. Physiol Behav 81:795-803.

Mizuno A, Matsumoto N, Imai M, Suzuki M (2003) Impaired osmotic sensation in mice lacking TRPV4. Am J Physiol Cell Physiol 285:C96-C101.

Muraki K, Iwata Y, Katanosaka Y, Ito T, Ohya S, Shigekawa M, Imaizumi Y (2003) TRPV2 is a component of osmotically sensitive cation channels in murine aortic myocytes. Circ Res 93:829-838.

Nissen R, Bourque CW, Renaud LP (1993) Membrane properties of organum vasculosum lamina terminalis neurons recorded in vitro. Am J Physiol 264:R811-R815.
O'Neil RG, Heller S (2005) The mechanosensitive nature of TRPV channels. Pflügers Arch 451:193-203.

Oldfield BJ, Bicknell RJ, McAllen RM, Weisinger RS, McKinley MJ (1991) Intravenous hypertonic saline induces Fos immunoreactivity in neurons throughout the lamina terminalis. Brain Res 561:151-156.

Oliet SH, Bourque CW (1993) Mechanosensitive channels transduce osmosensitivity in supraoptic neurons. Nature 364:341-343.

Rudelli R, Deck JH (1979) Selective traumatic infarction of the human anterior hypothalamus. Clinical anatomical correlation. J Neurosurg 50:645-654.

Sayer RJ, Hubbard JI, Sirett NE (1984) Rat organum vasculosum laminae terminalis in vitro: responses to transmitters. Am J Physiol 247:R374-R379.

Sharif Naeini R, Witty MF, Seguela P, Bourque CW (2006) An N-terminal variant of Trpv1 channel is required for osmosensory transduction. Nat Neurosci 9:93-98.

Sladek CD, Johnson AK (1983) Effect of anteroventral third ventricle lesions on vasopressin release by organ-cultured hypothalamoneurohypophyseal explants. Neuroendocrinology 37:78-84.

Strotmann R, Harteneck C, Nunnenmacher K, Schultz G, Plant TD (2000) OTRPC4, a nonselective cation channel that confers sensitivity to extracellular osmolarity. Nat Cell Biol 2:695-702.

Thrasher TN (1989) Role of forebrain circumventricular organs in body fluid balance. Acta Physiol Scand Suppl 583:141-150.

Thrasher TN, Keil LC (1987) Regulation of drinking and vasopressin secretion: role of organum vasculosum laminae terminalis. Am J Physiol 253:R108-R120.

Thrasher TN, Brown CJ, Keil LC, Ramsay DJ (1980) Thirst and vasopressin release in the dog: an osmoreceptor or sodium receptor mechanism? Am J Physiol 238:R333-R339.

Thrasher TN, Keil LC, Ramsay DJ (1982) Lesions of the organum vasculosum of the lamina terminalis (OVLT) attenuate osmotically-induced drinking and vasopressin secretion in the dog. Endocrinology 110:1837-1839.

Travis KA, Johnson AK (1993) In vitro sensitivity of median preoptic neurons to angiotensin II, osmotic pressure, and temperature. Am J Physiol 264:R1200-R1205.

Vivas L, Chiaraviglio E, Carrer HF (1990) Rat organum vasculosum laminae terminalis in vitro: responses to changes in sodium concentration. Brain Res 519:294-300.

Watanabe H, Vriens J, Prenen J, Droogmans G, Voets T, Nilius B (2003) Anandamide and arachidonic acid use epoxyeicosatrienoic acids to activate TRPV4 channels. Nature 424:434-438.

Wissenbach U, Bodding M, Freichel M, Flockerzi V (2000) Trp12, a novel Trp related protein from kidney. FEBS Lett 485:127-134.

Xu Z, Herbert J (1995) Regional suppression by lesions in the anterior third ventricle of $\mathrm{c}$-fos expression induced by either angiotensin II or hypertonic saline. Neuroscience 67:135-147. 